\title{
UV Spectrophotometric Method Development and Validation of Mesalazine in Bulk and Solid Dosage Form
}

\author{
Shrishail Ghurghure ${ }^{1}$, Kuldeepkumar Sawant ${ }^{1 *}$ and Savita S Deokar ${ }^{2}$ \\ 1D.S.T.S Mandal's College of Pharmacy, Solapur- 413004, Maharashtra, India. \\ 2Department of Pharmaceutics, PES, Modern College of Pharmacy, Nigidi, Pune
}

Received: 10 Oct 2020 / Accepted: 8 Nov 2020/ Published online: 01 Jan 2021 *Corresponding Author Email: kuldeepkumarsawant97@gmail.com

\begin{abstract}
Objective: A new, simple, sensitive, precise and reproducible UV spectroscopic method was developed for the estimation of Mesalazine in bulk and Tablet Formulation. Methods: The UV spectrum of Mesalazine in Triflouroacetic acid (0.1\%) showed $\lambda$ max at $300 \mathrm{~nm}$. Beer's law is valid in the concentration range of $10-50 \mu \mathrm{g} / \mathrm{ml}$. This method was validated for linearity, accuracy, precision, ruggedness, and robustness. Results: The method has demonstrated excellent linearity over the range of $10-50 \mu \mathrm{g} / \mathrm{ml}$ with regression equation $\mathrm{y}=0.017 \mathrm{x}+0.0637$ and regression correlation coefficient $r^{2}=0.9953$. Moreover, the method was found to be extremely sensitive with LOD $(5.67 \mu \mathrm{g} / \mathrm{ml})$ and LOQ $(17.19 \mu \mathrm{g} / \mathrm{ml})$. Conclusion: Depending on results the given method can be successfully applied for assay of Mesalazine in tablet formulation.
\end{abstract}

\section{Keywords}

Mesalazine, UV spectroscopy, method development and validation, Triflouroacetic acid water $0.1 \%$, Tablet Formulation.

$* * * * *$

\section{INTRODUCTION:}

Mesalazine is also called as mesalamine. It (5aminosalicylic acid) is an anti-inflammatory agent, structurally related to the salicylates, which is active in inflammatory bowel disease and active ulcerative proctitis. It is a tan to pink crystalline powder, relatively insoluble in chloroform, ether, $\mathrm{n}$-hexane and ethyl acetate and freely soluble in dil. $\mathrm{HCl}$ and alkali hydroxides. Mesalazine is available in tablet dosage forms (400 mg) and is an official drug of USP. The chemical structure of Mesalazine is shown in Figure 1.

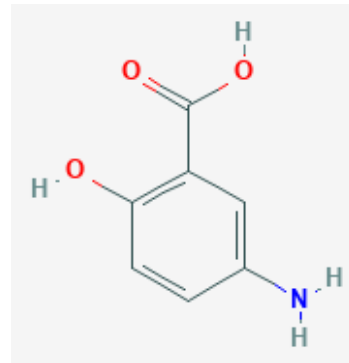

Fig 1: Chemical Structure of Mesalazine

Literature survey reveals that, some study about HPLC determination of Mesalamine and its degradation metabolite in plasma determination of 5-aminosalicylic acid in pharmaceutical formulation by differential pulse voltammetry. To the best of our knowledge, there is no UV method for the analysis of MSZ in pharmaceutical formulations has been reported in literature survey. 
The aim of this study is to develop a fast, simple, reliable, selective, and inexpensive UV spectrophotometric method for the determination of MSZ in bulk drug \& commercial pharmaceuticalformulations as tablet and its validation.

\section{MATERIALS AND METHOD:}

\section{Materials}

Mesalazine was taken as gift sample from Airis, Hyderabad. TFA $0.1 \%$ water was taken from local market. Other Analytical Grades Chemicals are used. Instruments:

UV/Visible double beam spectrophotometer Systronic 2201. Standard cuvettes having $10 \mathrm{~mm}$ of path length are used for analysis. Ultra Sonicator (micro clean-103) was used to sonicate the formulation sample. Drug sample was weighed by using an electronic analytical balance (Shimadzu AY220). Sonicator (Microclean-1103), UV-Visible (Labman).

\section{Experimental:}

Preparation of standard stock solution:

Accurately weighed $10 \mathrm{mg}$ of Mesalazine transferred to $100 \mathrm{ml}$ volumetric flask. It was dissolved $5 \mathrm{ml}$ in $0.1 \%$ TFA water \& sonicated for 5 minutes. The volume was made up to mark with same diluent to make up final strength.

\section{Procedure for plotting calibration curve:}

For calibration curve in a series of $10 \mathrm{ml}$ volumetric flasks, $1-5 \mathrm{ml}$ of standard solution was pipetted out separately. The volume was completed to the mark using $0.1 \%$ TFA water. The absorbance was measured at wavelength $300 \mathrm{~nm}$ against blank solution.

Analysis of Mesalazine in tablet Formulation:

10mg equivalent Mesalazine Tablet was weighed and transferred to the $100 \mathrm{ml}$ volumetric flask and dissolved in TFA water $0.1 \%$ as a solvent. After that sonicated for $5 \mathrm{~min}$ and vortex for $2 \mathrm{~min} .4 \mathrm{ml}$ of above solution was pipetted out and transferred to the $10 \mathrm{ml}$ volumetric flask and make up the volume upto the mark with same solvents and analysed at $300 \mathrm{~nm}$. Calculate the \% purity of Mesalazine.

\section{RESULTS AND DISCUSSION:}

The absorption spectrum shows $\lambda$ max of Mesalazine at $300 \mathrm{~nm}$.

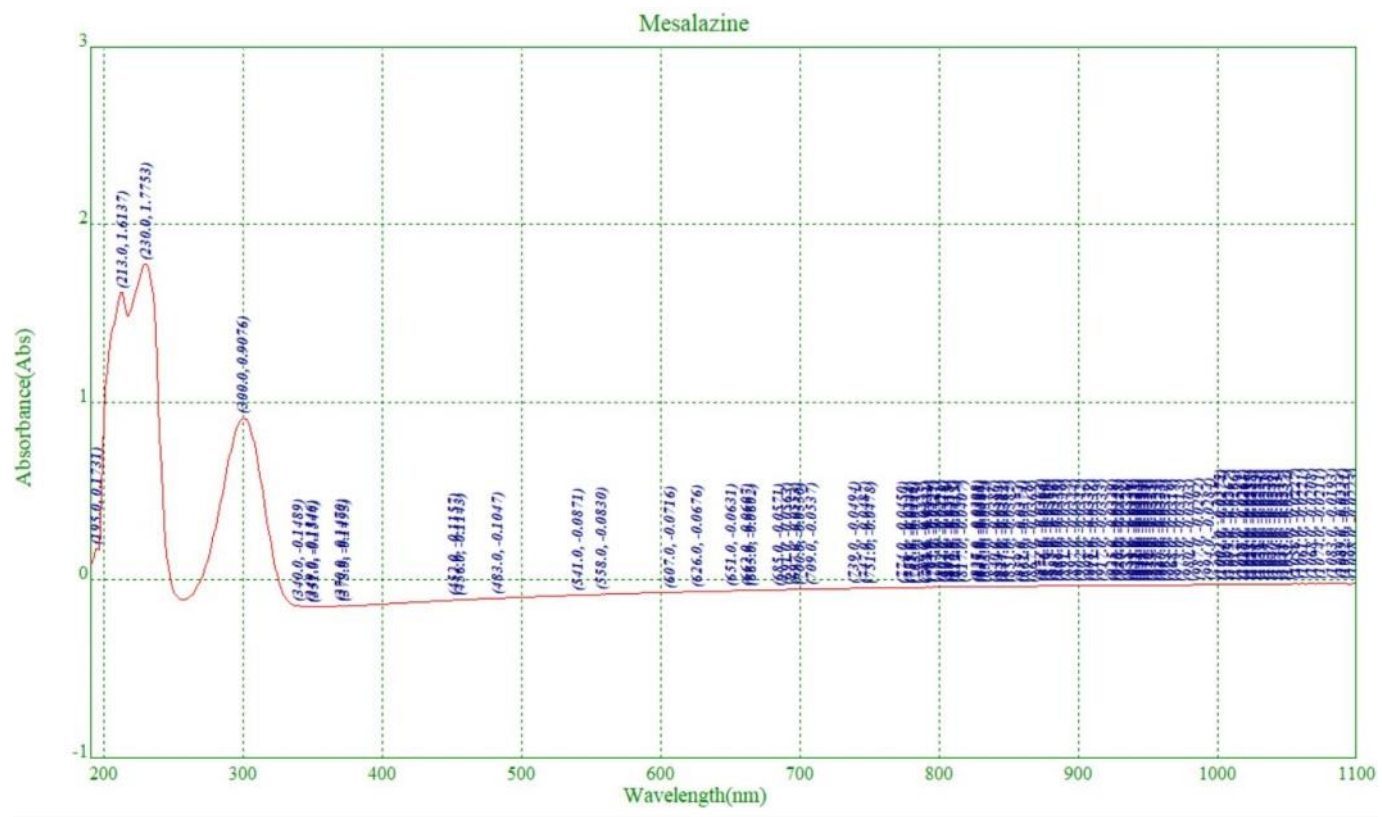

Figure 2: UV spectrum of Mesalazine

The proposed method was validated according to $\mathrm{ICH}$ Q28 R1 guidelines for validation of analytical procedure. ${ }^{4-8}$

Linearity:

Five different concentrations of Mesalazine were prepared and analysed at wavelength $300 \mathrm{~nm}$. The regression coefficient was found to be 0.9953 . The absorbance was found in limit i.e. 10-50. Hence the analysed parameter was found to be validated (table $1)$. 
Table 1: Results of Linearity

\begin{tabular}{lll}
\hline Sr.no. & Concentration $(\mu \mathrm{g} / \mathrm{ml})$ & Absorbance \\
\hline 1 & 10 & 0.215 \\
2 & 20 & 0.414 \\
3 & 30 & 0.601 \\
4 & 40 & 0.732 \\
5 & 50 & 0.907 \\
\hline
\end{tabular}

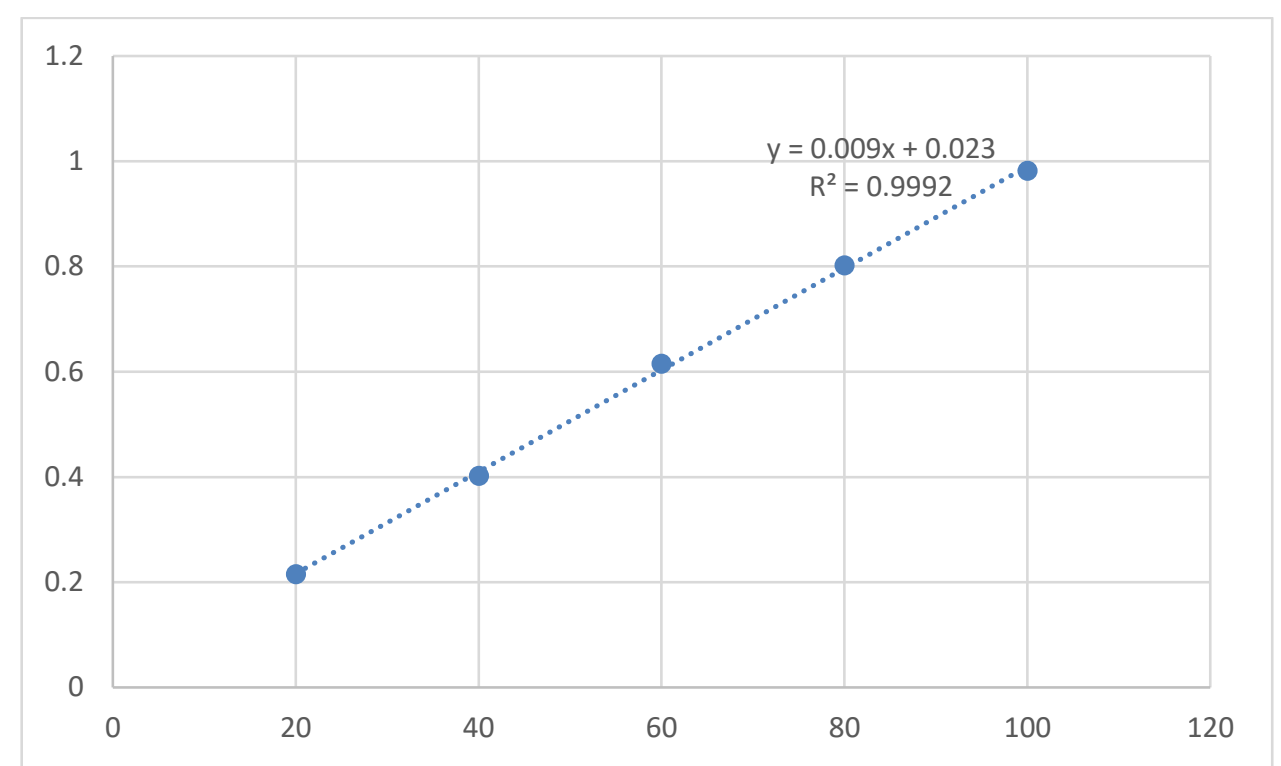

Figure 3: Calibration curve for Mesalazine (Conc. vs. Abs.)

Table 2: Optimization parameters of Mesalazine

\begin{tabular}{ll}
\hline Parameters & Method values \\
\hline Maximum Wavelength & $300 \mathrm{~nm}$ \\
Beer's Law & $10-50 \mu \mathrm{g} / \mathrm{ml}$ \\
Correlation Coefficient $\left(\mathrm{r}^{2}\right)$ & 0.9953 \\
Regression Equation & $\mathrm{y}=0.017 \mathrm{x}+0.0637$ \\
Slope $(\mathrm{m})$ & 0.017 \\
Intercept $(\mathrm{c})$ & 0.0637 \\
\hline
\end{tabular}

Accuracy:

The concentration $40,50,60 \mu \mathrm{g} / \mathrm{ml}$ was taken as $80,100,120 \%$ and $\%$ recovery was found to be in range $99 \%-101 \%$. Hence the parameter was found to be validated.

Table 3: Results of Accuracy

\begin{tabular}{lllll}
\hline Name of Drug & Recovery Level in \% & Concentration & Amount Recovered & \% recovery with SD \\
\hline \multirow{3}{*}{ Pentasa } & 80 & $40 \mu \mathrm{g} / \mathrm{ml}$ & 40.02 & $100.02 \pm 0.25$ \\
& 100 & $50 \mu \mathrm{g} / \mathrm{ml}$ & 50.03 & $100.03 \pm 0.7$ \\
& 120 & $60 \mu \mathrm{g} / \mathrm{ml}$ & 59.01 & $99.01 \pm 0.29$ \\
\hline
\end{tabular}

\section{Range:}

Range is an interval between highest and lowest concentration limit of the analyte i.e. $10-50 \mu \mathrm{g} / \mathrm{ml}$.
Precision:

In precision intra-day and inter-day precision were performed at concentration $(50 \mu \mathrm{g} / \mathrm{ml})$. The obtained results were found within limit i.e., less than $2 \%$ RSD. 
Table 4: Results of Intra-day Precision

\begin{tabular}{lll}
\hline Sr. no. & Concentration & Absorbance \\
\hline 1 & & 0.9076 \\
2 & 0.9137 \\
3 & 0.9135 \\
4 & 0.9128 \\
5 & 0.913 \\
6 & 0.9122 \\
\hline & SD: & $\mathbf{0 . 0 0 2 6 1 8}$ \\
& \%RSD: & $\mathbf{0 . 2 9}$
\end{tabular}

Table 5: Results of Inter-day precision

\begin{tabular}{llll}
\hline Sr.no. & Concentration & Absorbance (Day1) & Absorbance (Day2) \\
\hline 1 & 0.9076 & 0.9082 \\
2 & & 0.9137 & 0.9142 \\
3 & $(50 \mu \mathrm{g} / \mathrm{ml})$ & 0.9135 & 0.9135 \\
4 & 0.9128 & 0.9135 \\
5 & 0.913 & 0.9142 \\
6 & & 0.9122 & 0.9102 \\
\hline & SD: & $\mathbf{0 . 0 0 2 6 1 8}$ & 0.002503 \\
& \%RSD: & $\mathbf{0 . 2 9}$ & 0.274339 \\
\hline
\end{tabular}

Limit of Detection (LOD): The limit of detection (LOD) is the lowest concentration of an analyte in a sample that can be detected but not necessarily to be determined quantitatively under specified experimental conditions. The limit of detection, as calculated statistically for mesalamine was found to be to be $5.37 \mu \mathrm{g} / \mathrm{ml}$.

\section{Limit of Quantification (LOQ):}

The limit of quantification (LOQ) is the lowest concentration of an analyte in a sample that can be quantitatively determined within an acceptable level of accuracy and precision under the stated operational conditions of the method. The limit of quantification was found to be $17.19 \mu \mathrm{g} / \mathrm{ml}$.

\section{Ruggedness}

The change in analyst with same concentration and environmental condition did not affect the results.

Table 6: Results of Ruggedness

\begin{tabular}{rll}
\hline Concentration & Absorbance (Analyst1) & Absorbance (Analyst2) \\
\hline & 0.413 & 0.414 \\
& 0.412 & 0.413 \\
& 0.413 & 0.413 \\
& 0.411 & 0.414 \\
& 0.412 & 0.413 \\
& 0.412 & 0.412 \\
Average: & $\mathbf{0 . 4 1 2 5}$ & $\mathbf{0 . 4 1 3 1}$ \\
SD: & $\mathbf{0 . 0 0 0 7 5 3}$ & $\mathbf{0 . 0 0 0 7 2 5}$ \\
\hline
\end{tabular}

Robustness:

The change in wavelength $(300 \mathrm{~nm}$ and $305 \mathrm{~nm})$ and concentration $(30 \mu \mathrm{g} / \mathrm{ml})$ didn't affect the results. 
Table 8: Results of Robustness

\begin{tabular}{|l|l|l|}
\hline Wavelength & $300 \mathrm{~nm}$ & $305 \mathrm{~nm}$ \\
\hline Concentration & $30 \mu \mathrm{g} / \mathrm{ml}$ & $30 \mu \mathrm{g} / \mathrm{ml}$ \\
\hline Absorbance & 0.601 & 0.611 \\
\cline { 2 - 3 } & 0.602 & 0.612 \\
\cline { 2 - 3 } & 0.602 & 0.612 \\
\cline { 2 - 3 } & 0.602 & 0.613 \\
\cline { 2 - 3 } & 0.601 & 0.611 \\
\cline { 2 - 3 } & 0.603 & 0.612 \\
\hline Average & $\mathbf{0 . 6 0 1 8 3 3}$ & $\mathbf{0 . 6 1 1 8 3 3}$ \\
\hline SD & $\mathbf{0 . 0 0 0 7 5 3}$ & $\mathbf{0 . 0 0 0 7 3 5}$ \\
\hline
\end{tabular}

Assay:

The assay was performed by using Pentasa at concentration $40 \mu \mathrm{g} / \mathrm{ml}$. The $\%$ purity was found to be 99.57

Table 9: Results of Assay

\begin{tabular}{llll}
\hline Formulation & Labeled Amount & Amount obtained & \% purity \\
\hline Pentasa & 500 & 499.55 & $99.57 \%$ \\
\hline
\end{tabular}

\section{CONCLUSION:}

An analytical UV spectrophotometric method was developed \& validated thoroughly for quantitative determination of Mesalazine in bulk drug and tablet formulation. The presented method was found to be simple, precise, accurate, rugged, and reproducible and gives an acceptable recovery of the analyte, which can be directly easily applied to the analysis of pharmaceutical Tablet formulation of Mesalazine.

\section{ACKNOWLEDGEMENT:}

The authors are thankful to the Principal Dr. R. Y. Patil sir, D.S.T.S Mandal's College of Pharmacy Solapur, for providing the facilities and continuously support for carried out this Research Programme.

\section{REFERENCES:}

1. Vani R, Sunitha M. Analytical method development and validation for the determination of Acotiamide hydrochloride using reverse phase HPLC method in bulk and tablet dosage form. World journal of pharmacy and pharmaceutical sciences. 2010; 6(10):768-775.

2. Patel PN, Kalariya PD, Swamy CV, Gananadhamu S, Srinivas R. Quantitation of Acotiamide in rat plasma by UHPLC-Q-TOF-MS: method development, validation and application to pharmacokinetics. Biomed Chromatography. 2016; 30(3): 363-368.

3. Klaus Florey, Lidocaine Base and Hydrochloride, Analytical Profiles of Drug Substances, Chapter 8, page 207-243.

4. Deepak v. Bageshwar, avinash s. Pawar, vineeta v. Khanvilkar, vilasrao j. Kadam. Quantitative
Estimation Of Mupirocin Calcium From Pharmaceutical Ointment Formulation By Uv Spectrophotometry, International Journal of Pharmacy and Pharmaceutical Sciences ISSN- 09751491 Vol 2, Issue 3, 2010.

5. ICH Q2 (R1) validation of analytical procedures: text and methodology, International Conference on Harmonization, Nov 1996.

6. Raut CS, Charge DS, Dhabale PN, Gonjari ID, Hosmani $\mathrm{AH}$, Hosmani AH. Development and validation of oseltamivir phosphate in fluvir by uvspectrophotometer. Int J Pharma Tech Res 2010; 2:363-6.

7. Sahu SA, Acharya SA, Chourasia AK, Asati AP. Method development and validation of Oseltamivir phosphate in bulk drug by uv spectroscopy. Int J Pharm Pharm Sci 2012; 4:194-6.

8. Davies BE. Pharmacokinetics of oseltamivir: an oral antiviral for the treatment and prophylaxis of influenza in diverse populations. J Antimicrob Chemother 2010; 65:5-10.

9. Pandian PM, Kannan KK, Manikandan MP, Manavalan Rk. Formulation and evaluation of oseltamivir phosphate capsules. Int J Pharm Pharm Sci 2012; 4:342-7.

10. https://www.rochecanada.com/PMs/Tamiflu/Tamifl U_PM_E.pdf. [Last accessed on 02 Oct 2019]

11. Ward PP, Small IJ, Smith JJ, Suter PP, Dutkowskr RO. Oseltamivir (Tamiflu) and it's potential for use in the event of an influenza pandemic. I Antimicrob Chemother 2005; 5:5-21. 